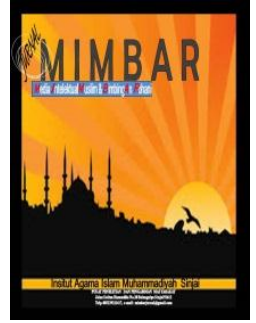

Volume 7, No. 2, 2021

ISSN (print) : 2442-3217 / ISSN (online) : 2716-3806

Email : mimbarjurnal@gmail.com

Homepage : http://journal.iaimsinjai.ac.id/indeks.php/mimbar

DOI $\quad:$ https://doi.org/10.47435/mimbar.v7i2

\title{
STRATEGI MENGATASI TRAUMA PADA KORBAN BULLYING MELALUI KONSELING EKSISTENSIAL
}

\author{
Syafrianto Tambunan \\ Institut Agama Islam Negeri Padangsidimpuan, Sumatra Utara \\ Email: jasnonebo21@gmail.com
}

\begin{abstract}
Bullying is a behavior that does not please those who feel it and makes people tend to be someone who has a closed nature or is more aloof from the crowd. In recent years there have been many cases of bullying that have occurred and this has experienced an increase in its spread to the extent that it has a negative impact on the sufferer, namely a sense of trauma that arises until it is sustainable and for quite a long time. Trauma is a nature in which the victim will feel a sense of anxiety, anxiety, emotions and behavior that lose control and fear appears instantly. As for problems like this, they must be addressed as soon as possible because they are afraid that they will get worse and the methods of alleviation will also vary and allow problems to arise in daily life. The strategy used is existential counseling in which there are several concepts, namely trauma, bullying, some signs of bullying, the impact of bullying, the existential counseling process, the goals of existential counseling, the function and role of the counselor, the role of the client in counseling, how the client's relationship with the counselor in counseling activities, and how to overcome trauma in existential counseling.
\end{abstract}

Keywords: Oppression; existential counseling; trauma

\begin{abstract}
ABSTRAK
Bully adalah suatu perilaku yang tidak menyenangkan hati orang-orang yang merasakannya serta membuat orang cenderung menjadi seseorang memiliki sifat tertutup atau lebih menyendiri dari keramaian. Pada akhir-akhir tahun ini banyak kasus bullying yang terjadi dan ini mengalami suatu peningkatan dalam menyebarnya luas hingga membuat dampak yang buruk bagi sipenderita yaitu suatu rasa trauma yang timbul hingga berkelanjutan dan sampai waktu yang cukup lama sekali. Trauma adalah sifat yang dimana korban akan merasakan suatu rasa yang gelisah, adanya kecemasan, adanya emosi dan perilaku yang hilang control serta rasa takut pun muncul seketika. Adapun permasalah yang seperti ini harus diatasi segera mungkin karena ditakutkan akan semakin parah dan cara pengentasannya pun akan beragam pula dan memungkinkan masalah akan timbul dalam keseharian. Adapun strategi yang digunakan ialah konseling eksistensial yang didalam nya ada beberapa konsep yaitu trauma, bullying, beberapa tanda bullying, dampak bullying, proses konseling eksistensial, tjuan konseling eksistensial, fungsi dan peran konselor, adanya peran klien dalam konseling, bagaimana hubungan klien dengan konselor dalam kegiatan konseling, dan cara mengatasi trauma dalam konseling eksistensial.
\end{abstract}

Kata kunci: Bullying; Konseling eksistensial; Trauma 


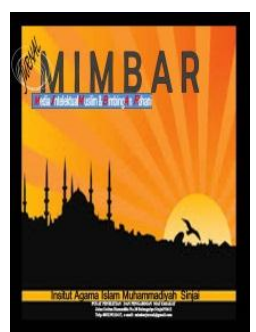

Volume 7, No. 2, 2021

ISSN (print) : 2442-3217 / ISSN (online) : 2716-3806

Email : mimbarjurnal@gmail.com

Homepage : http://journal.iaimsinjai.ac.id/indeks.php/mimbar

DOI

: https://doi.org/10.47435/mimbar.v7i2

\section{PENDAHULUAN}

Bullying ini jika terjadi pada diri seseorang maka akan berdampak sangat menyakitkan bagi korban, dan ini akan membuat masalah bagi korban sehingga menimbulkan berbagai kondisi negatife yang akan membuat orang disekitarnya merasakan keanehan maupun menghindar dari diri korban. Salah satu kondisi negatif yang terjadi akibat bullying adalah trauma. Trauma akibat bullying akan membuat dampak yang buruk bagi korban bullying seperti korban akan merasa bahwa dirinya itu selalu ketakutan, merasa dirinya gelisah, kecemasan selalu menghampiri nya seakan-akan dia merasa bahwa dirinya tidak berguna serta perilaku yang tidak terkontrol pun akan muncul seketika pada diri korban. Disini harus ada metode ataupun cara yang tepat untuk segera mengatasi masalah ini karena ini merupakan masalah yang urgen sekali jika tidak secepat mungkin diatasi. Menurut kasus yang terjadi pada tahun 2017 di Indonesia sehingga menjadi suatu topik pembicaran yaitu korban bullying pada anak SMP yang siswa nya itu berasal dari Thamrin City, dimana kasus bullying yang korban yaitu mahasiswa yang berkebutuhan khusus di University Gunadarma.

Menurut Coloroso yang mencantumkan bahwa suatu perbuatan bullying ini memiliki 3 aspek yaitu bullying verbal, bullying fisik, bullying psikologis. Adapun bullying ialah suatu perilaku yang mengina, mengejek, memaki, berkata kasar, mencela. Jika bullying fisik yaitu suatu perilaku yang berkenaan dengan memukul, meninju, menendang, meludahi, bahkan melukai. Kalau bagian bullying psikologis ini dengan adanya suatu pencemaran nama baik yang korban merasa bahwa dirinya dijauhi dan pandangan orang itu jelek mengenai dirinya.

Dan terjadilah suatu dampak yang membuat korban merasa bahwa dirinya mulai terasingkan dari kelompok serta teman sosial. Jika sudah terjadi seperti ini maka akan muncullah rasa trauma yang berkepanjangan terlebih lagi jika cara penanganannya tidak ditemui segera dengan tepat dan cepat. Adapun cara penanganan yang dilakukan adalah dengan melakukan yang namanya konseling eksistensial, yang konseling ini adalah suatu konseling yang mendasar serta membuat korban sadar akan diri, adanya kebebasan, rasa tanggung jawab, ingin 


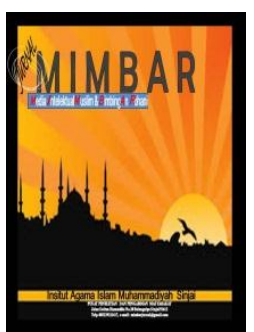

MIMBAR

Jurnal Media Intelektual Muslim dan Bimbingan Rohani

Volume 7, No. 2, 2021

ISSN (print) : 2442-3217 / ISSN (online) : 2716-3806

Email : mimbarjurnal@gmail.com

Homepage : http://journal.iaimsinjai.ac.id/indeks.php/mimbar

DOI

: https://doi.org/10.47435/mimbar.v7i2

mendapat jati diri sehingga bisa bergaul dengan layak, pencarian makna, kecemasa akan suatu keadaan hidup, kesadaran akan kematian dan ketiadaan.

Konseling eksistensial ini adalah dimana akan diberi suatu penjelasan pada korban agar sadar akan diri sendiri sehingga mampu memahami dirinya. Sifat trauma ini adalah dimana korban memiliki sifat yang tersakiti, terluka, sedih seakan-akan tiada harapn untuk hidup, rasa tidak berguna, disinilah konseling eksistensial ini berusaha untuk mengubah pola piker dari korban trauma sehinggan melahirkan kembali seorang individu yang mencintai dirinya dan mempunyai kehidupan yang lebih bermakna.

\section{Metede}

Jenis dan pendekatan dalam penelitian ini yaitu jenis penelitian Pustaka dengan pendekatan Kualitatif deskriptif.penelitian ini dengan metode kualitatif. Penelitian ini berdasarkan sumber kepustakaan (library research) berupa buku, jurnal,media elektronik maupun sumber- sumber ilmiah lainnya yang berhubungan dengan penulisan. Dalam pembahasan penelitian ini menggunakan model deskriptif analitik, yaitu berusaha menggambarkan secara objektif keadaan yang sebenarnya dari masalah-masalah yang diteliti, kemudian dianalisa sehingga menjadi jelas dan diketahui letak model konsepnya.

\section{Hasil dan Pembahasan}

\subsection{Trauma}

Trauma adalah suatu gangguan psikologis yang sangat berbahaya dan ini mampu merusak suatu keseimbangan diri dalam kehidupan, Cavanagh berpendapat bahwa tentang defenisi dari trauma ini ialah suatu peristiwa yang sangat luar biasa serta sangat berpengaruh besar dalam kehidupan karena jika terjadi bisa menimbulkan luka, perasaan sakit, namun sering juga diartikan bahwa luka yang luar biasa bisa terjadi pasti diakibatkan hal yang luar biasa pula secara langsung maupun tidak baik luka fisik maupun luka psikis atau juga kombinasi keduanya adapun dampak yang terjadi ini pun akan ada perbedaan setiap orang yang merasakannya karena setiap orang itu berbeda-beda mulai dari angka 0 sampai 10 maka orang pun akan berbeda rasa dan pengaruh yang timbul. 


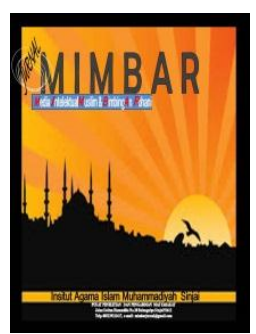

MIMBAR

Jurnal Media Intelektual Muslim dan Bimbingan Rohani

Volume 7, No. 2, 2021

ISSN (print) : 2442-3217 / ISSN (online) : 2716-3806

Email : mimbarjurnal@gmail.com

Homepage : http://journal.iaimsinjai.ac.id/indeks.php/mimbar

DOI $\quad:$ https://doi.org/10.47435/mimbar.v7i2

Adapun jenis-jenis dari trauma, Cavanagh (Hatta, 2016) mengelompokkan bahwa trauma berdasarkan akan suatu peristiwa yang trauma yang ada disini juga ada beberapa tipe-tipe dari trauma digolongkan menjadi 4 bagian yaitu:

\subsubsection{Trauma situasional}

Trauma ini adalah suatu trauma yang keterkaitan dengan adanya suatu perubahan kondisi maupun situasi seperti adanya kebakaran, bencana alam, meninggal orang yang dicintai, dipecat, kegagalan dalam usaha, dan kecelakaan.

\subsubsection{Trauma perkembangan}

Trauma perkembangan ini terjadi karena suatu perkembangan ini sangat tidak diinginkan seperti penolakan sebaya, trauma yang berkaitan dengan kencan, keluarga maupun rekan yang setiap perkembangannya itu tidak diinginkan karena adanya perubahan.

\subsubsection{Trauma intrapsikis}

Trauma intrapsikis dimana korban merasa bahwa dirinya selalu merasa takut, ragu, serta kecemasan yang kuat seperti aka nada munculnya homo seksual, terlihatnya sifat yang awalnya mencintai jadi membenci dan ini suatu perilaku yang ketakutannya sangat berlebihan.

\subsubsection{Trauma eksistensial}

Trauma eksistensial ini cenderung kepada suatu kegagalan yang berakibat munculnya rasa putus asa, tidak bermakna nya hidup. Disini korban merasa ingin mengakhiri hidupnya tanpa alasan yang jelas.

\subsection{Bullying}

Mencantumkan bahwa bullying adalah suatu perilaku yang negative membuat korban merasakan ketidaksenangan dan menyakitkan dalam jangka waktu yang cukup lama bagi individu maupun kelompok yang man perilaku ini dilakukan berulang-ulang dengan unsur kesengajaan untuk menyakiti korban baik secara fisik maupun psikis (Olweus, 2006). Dilakukan bullying ini dengan penuh kesadaraan yang mana ini dilakukan untuk menekan individu yang lemah saja dimana individu ini tidak melawan ataupun suatu kelompok yang lemah di dikucil kan oleh kelompok yang lain tetapi memberikan respon untuk membalas 


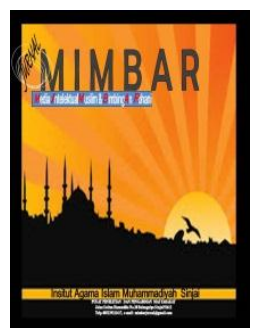

Volume 7, No. 2, 2021

ISSN (print) : 2442-3217 / ISSN (online) : 2716-3806

Email : mimbarjurnal@gmail.com

Homepage : http://journal.iaimsinjai.ac.id/indeks.php/mimbar

DOI

: https://doi.org/10.47435/mimbar.v7i2

perbuatan mereka. Maka dari sinilah akan timbul kerugian pada diri korban sehingga muncul lah perilaku yang negative.

\subsubsection{Tanda-tanda Bullying}

Dalam memahami bullying ada beberapa hal yang harus dikenal sebagai tandatanda bullying. Menurut (Coloroso, 2007) bullying mengandung tiga elemen yaitu kekuatan yang tidak seimbang, bertujuan untuk menyakiti, dan adanya ancaman akan dilakukannya agresi. (Olweus, 2006) bullying memiliki tiga unsur yaitu menyerang dan negatif, dilakukan secara berulang kali, dan adanya ketidakseimbangan kekuatan antara pihak yang terlibat. Tanda-tanda bullying akan membantu dalam mengenal pelaku sebelum melakukan bullying hal ini akan dapat mencegah lebih awal proses terjadinya bullying. Ada beberapa bentuk bullying yang sering terjadi pada korban sehingga menimbulkan trauma. Menurut (Sullivan et al., 2003) yaitu bullying fisik merupakan tindakan yang yang dilakukan pelaku melalui tindakan fisik atau menyentuh korban seperti memukul, menendang, meninju, meludahi dan mendorong, bullying psikologis berupa bullying verbal dan non verbal. Bullying verbal yaitu tindakan yang dilakukan pelaku bullying seperti menghina, mengejek bahkan berbicara kasar, bullying non verbal yaitu tindakan pelaku bullying seperti merusak persahabatan melalui fitnah.

\subsubsection{Dampak Bullying}

Bullying merupakan tindakan yang agresif, merugikan dan dapat mengakibatkan ketidak nyamanan dan trauma bagi korban. Dampak bullying menurut (Coloroso, 2007) yaitu mengakibatkan depresi dan kemarahan. Swearer, dkk (2010) korban bullying juga merasa sakit, menjauhi sekolah, prestasi akademik menurun, rasa takut dan kecemasan meningkat, adanya keinginan bunuh diri, serta dalam jangka panjang akan mengalami kesulitan-kesulitan internal yang meliputi rendahnya self esteem, kecemasan, dan depresi. Dampak bullying berakibat sangat mengerikan apabila korban tidak dibantu dalam menyelesaikan masalahnya. Proses pencegahan menjadi hal mutlak yang harus dilakukan tetapi bagi korban yang sudah mengalami maka diperlukan solusi 


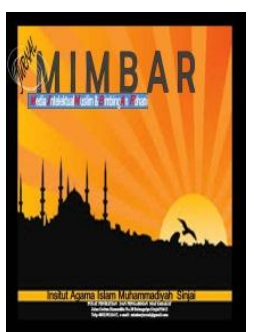

Volume 7, No. 2, 2021

ISSN (print) : 2442-3217 / ISSN (online) : 2716-3806

Email : mimbarjurnal@gmail.com

Homepage : http://journal.iaimsinjai.ac.id/indeks.php/mimbar

DOI $\quad:$ https://doi.org/10.47435/mimbar.v7i2

sehingga masalah yang di hadapinya dapat terselesaikan dan korban dapat keluar dari masalah yang dihadapinya.

\subsection{Teori dan Prinsip Dasar Hakekat Manusia}

\subsubsection{Pandangan Tentang Hakekat Manusia}

Menurut (Corey, 2005) menjelaskan bahwa pandangan eksistensial mengenai hakekat manusia sebagian di kontrol oleh pendapat bahwa signifikansi dari keberadaan kita ini tidak pernah tetap, melainkan kita secara terus menerus mengubah diri sendiri melalui proyek-proyek kita. Manusia adalah makhluk yang selalu dalam keadaan transisi, berkembang, membentuk diri dan menjadi sesuatu. Dalam kehidupan ini pertanyaan dasar selalu ditanyakan pada diri kita "siapakah saya ini?, selama ini saya ini siapa?, saya akan menjadi siapa nanti?, kemana arah yang saya tuju?”.

Dalam konseling eksistensial, dimensi dasar dari kondisi manusia mencangkup hal-hal sebagai berikut kapasitas kesadaran diri, kebebasan serta tanggung jawab, menciptakan identitas dirinya dan menciptakan hubungan yang bermakna dengan orang lain, usaha pencarian makna, tujuan, nilai dan sasaran, kecemasan sebagi suatu kondisi hidup serta kesadaran akan datangnya maut serta ketidakberadaan.

\subsubsection{Kapasitas Kesadaran Diri}

Sebagai umat manusia kita bisa mengenang kembali dan menentukan pilihan oleh karena itu kita mampu menyadari diri kita sendiri. Makin tebal kesadaran, semakin besar kemungkinan kita untuk mendapatkan kebebasan. Oleh sebab itu mengembangkan kesadaran kita adalah meningkatkan kemampuan kita untuk hidup secara penuh.

\subsubsection{Kebebasan dan Tanggung Jawab}

Menurut eksistensial orang itu bebas untuk menentukan pilihan di antara alternatif-alternatif yang ada dan oleh karenanya mengambil peranan yang besar dalam menentukan nasib sendiri. Meskipun kita dulu tidak ada pilihan untuk dilahirkan atau tidak, cara kita hidup dan menjadi apa kita nanti merupakan hasil dari pilihan-pilihan yang telah kita tentukan. Oleh karena itu realitas dari 


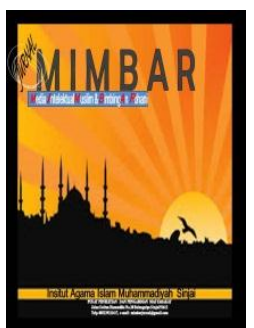

Volume 7, No. 2, 2021

ISSN (print) : 2442-3217 / ISSN (online) : 2716-3806

Email : mimbarjurnal@gmail.com

Homepage : http://journal.iaimsinjai.ac.id/indeks.php/mimbar

DOI

: https://doi.org/10.47435/mimbar.v7i2

kebebasan yang esensial adalah menerima tanggung jawab dari arah hidup yang telah kita tentukan sendiri itu.

\subsubsection{Menciptakan Identitas Dirinya dan Menciptakan Hubungan yang Bermakna dengan Orang Lain}

Manusia selalu ingin menemukan diri sendiri yaitu menemukan identitas diri sendiri. Hal ini tidak lahir dengan sendirinya atau secara otomatis tetapi diperlukan perjuangan. Dalam menciptakan identitas diri diperlukan keberanian untuk ada, mengalami kesendirian dan mengalami ketertarikan.

\subsubsection{Pencarian Makna}

Karakteristik manusia yang khas adalah perjuangan demi rasa signifikan dan adanya tujuan dalam hidup ini. Dalam konseling eksistensial bisa memberikan kerangka konseptual untuk menolong klien menantang makna dalam hidupnya. Pertanyaan yang mungkin diajukan oleh konseli adalah "apakah anda senang dengan arah hidup anda?, apakah anda senang dengan keadaan anda sekarang dan nanti?, apakah secara aktif anda berbuat sesuatu untuk dapat lebih dekat dengan ideal diri anda sendiri?, apakah anda tahu dengan yang anda inginkan? apa yang anda lakukan untuk mendapat kejelasan. dalam pencarian makna, klien mengalami hal-hal sebagai berikut yaitu problema membuang nilai lama, ketidak bermaknaan dan menciptakan makna baru.

\subsubsection{Kecemasan Sebagai Suatu Kondisi}

Bermula dari usaha seseorang untuk tetap hidup dan untuk mempertahankan dan tetap menekankan arti pada keberadaannya, maka ia harus berkonfrontasi dengan kecemasan sebagai bagian dari kondisi manusia yang tidak terelakkan. Konseling eksistensial membedakan kecemasan biasa dan neurotik. Kecemasan biasa merupakan tanggapan yang cukup wajar terhadap peristiwa yang dihadapi. kecemasan neurotik merupakan kecemasan yang keluar dari proporsi situasi yang ada, biasanya kecemasan jenis ini terjadi diluar kesadaran dan cenderung untuk menjadikan orang tidak memiliki mobilitas.

\subsubsection{Kesadaran akan Kematian dan Ketiadaan}

Kaum eksistensialis tidak memandang kematian sebagai hal yang negatif tetapi beranggapan bahwa kesadaran akan datangnya maut sebagai kondisi 


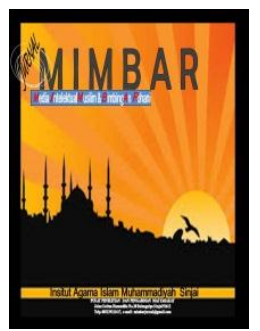

Volume 7, No. 2, 2021

ISSN (print) : 2442-3217 / ISSN (online) : 2716-3806

Email : mimbarjurnal@gmail.com

Homepage : http://journal.iaimsinjai.ac.id/indeks.php/mimbar

DOI

: https://doi.org/10.47435/mimbar.v7i2

manusia itu memberi arti yang penting pada hidup. Karakteristik manusia yang menonjol adalah kemampuannnya untuk menangkap realitas dari apa yang akan terjadi dan kenyataan bahwa maut adalah hal yang tidak bisa dihindari. Apabila kita harus memikirkan tentang hidup secara signifikan maka kita harus berfikir tentang maut.

\subsection{Konseling Eksistensial}

Tujuan Konseling Eksistensial Menurut (Corey, 2005) tujuan konseling eksistensial adalah agar klien mengalami keberadaan secara otentik dengan menjadi sadar atas keberadaan dan potensi-potensi dan sadar bahwa ia dapat membuka diri berdasarkan kemampuannya. Selain itu konseling eksistensial dapat membantu klien mengidentifikasi/menetapkan kegiatan-kegiatan yang berhubungan dengan perubahan kepribadian. perubahan itu meliputi perubahan yang menghasilkan keadaan baru, perubahan yang berisfat permanen dan bisa diterapkan klien dalam kehidupan seharihari diluar sesi konseling.

\subsubsection{Fungsi dan Peranan Konselor}

Dalam konseling eksistensial, konselor adalah memahami dunia subyektif klien agar bisa menolongnya untuk sampai pada pemahamanpemahaman pilihan baru. Fokusnya adalah pada situasi hidup klien pada saat itu dan bukan pada menolong klien agar bisa sembuh dari situasi masa lalu. Konselor yang berorientasi eksistensial biasanya menangani orang-orang yang mengalami apa yang dikatakan kesadaran terbatas. Tugas sentrla dari konselor adalah langsung mengkonfrontasikan klien ini dengan cara hidup mereka dalam keberadaan terbatas ini dan menolong mereka untuk bisa menyadari bahwa mereka ikut berperan dalam menciptakan kondisi semacam itu (Corey, 2005).

\subsubsection{Peran Klien Dalam Hubungan Konseling}

Dalam proses konseling klien harus aktif, sehingga dalam konseling harus menentukan rasa takut dan kecemasan yang mereka eksplorasi. Menurut (Corey, 2005) dalam konseling eksistensial, klien bertugas membuka pintu bagi dirinya sendiri setelah itu klien bertugas berkonfrontasi dengan kepedulian jauh kedepan dan bukan mengurusi problem-problem yang akan segera datang.

\subsubsection{Hubungan antara Konselor dan Klien Dalam Proses Konseling}




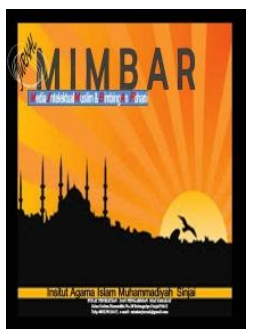

Volume 7, No. 2, 2021

ISSN (print) : 2442-3217 / ISSN (online) : 2716-3806

Email : mimbarjurnal@gmail.com

Homepage : http://journal.iaimsinjai.ac.id/indeks.php/mimbar

DOI

: https://doi.org/10.47435/mimbar.v7i2

Dalam konseling eksistensial hal yang paling utama adalah hubungan dengan konseli. Kualitas dari dua orang yang bertatap muka dalam situasi terapeutik ini merupakan stimulus terjadinya perubahan positif. Konselor berbagi reaksi dengan kliennya disertai kepedulian dan empati yang tidak di buat-buat sebagai cara untuk memantapkan hubungan terapeutik (Corey, 2005).

\subsubsection{Prosedur Konseling}

Ada tiga tahap proses konseling yaitu tahap pendahuluan konselor membantu klien dalam mengidentifikasi dan mengklarifikasi asumsi mereka tentang dunia (Corey, 2005). Klien diajak untuk mendefinisikan dan menanyakan tentang cara mereka memandang dan menjadikan eksistensi mereka bisa diterima. Mereka meneliti nilai mereka, keyakinan, serta asumsi untuk menentukan kesahihannya. Bagi banyak klien hal ini bukan pekerjaan yang mudah, oleh karena itu awalnya mereka memaparkan problema mereka. Konselor disini mengajarkan mereka bagaimana caranya untuk bercermin pada eksistensi mereka sendiri dan meneliti peranan mereka dalam hal penciptaan problem mereka dalam hidup. Tahan tengah, klien didorong semangatnya untuk lebih dalam lagi meneliti sumber dan otoritas dari sistem nilai mereka. Proses eksplorasi diri ini biasanya membawa klien ke pemahaman baru dan berapa restrukturisasi dari nilai dan sikap mereka. Klien mendapat cita rasa yang lebih baik akan jenis kehidupan macam apa yang mereka anggap pantas. Mereka mengembangkan gagasan yang jelas tentang proses pemberian nilai internal mereka. Tahap akhir, konseling eksistensial berfokus pada menolong klien untuk bisa melaksanakan apa yang telah mereka pelajari tentang diri mereka sendiri. Sasaran terapi adalah memungkinkan klien untuk bisa mencari cara pengaplikasikan nilai hasil penelitian dan internalisasi dengan jalan kongkrit. Biasanya klien menemukan jalan mereka untuk menggunakan kekuatan itu demi menjalani kesistensi kehidupannya yang memiliki tujuan.

\subsubsection{Teknik Konseling}

Ada empat teknik yang menjadi asumsi, keempat teknik ini menunjukan perbedannya dengan pendekatan dari konseling yaitu Paradoxical intention yaitu mendorong klien untuk mengikhtiarkan apa yang mereka hindari, menganut apa 


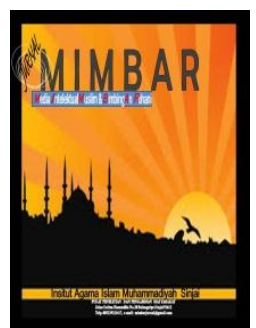

Volume 7, No. 2, 2021

ISSN (print) : 2442-3217 / ISSN (online) : 2716-3806

Email : mimbarjurnal@gmail.com

Homepage : http://journal.iaimsinjai.ac.id/indeks.php/mimbar

DOI

: https://doi.org/10.47435/mimbar.v7i2

yang mereka lawan mengganti kekuatan dengan harapan (Erford, 2016). Menurut (Corey, 2005) Paradoxical intention membantu klien menyadari bagaimana mereka berperilaku dalam situasi tertentu dan bertanggung jawab mereka atas perilaku itu. Paradoxical intention biasa digunakan dalam menciptakan motivasi pada seseorang yang kehilangan semangat (Erford, 2016). Focusing menurut Gendlin dalam (Uman, 2008) yaitu menciptakan kondisi fisik yang mnyenangkan, menghindari hal-hal yang mengganggu dalam kehidupan sehari-hari dan kembali pada suasana batin. Situational recontruction yaitu untuk memberikan ide tentang perubahan yang mengakibatkan ekspresi dari imaginasi bersemangat/giat. Dalam teknik situational recontruction lebih menekankan pada pertimbangan situasional dari pada konsekuensi emosi itu sendiri. Teknik ini berguna bagi klien yang mengalami stress. Compensatory self-improvement, bertujuan untuk meningkatkan pengertian/perasaan klien dari kemungkinan daerah lain dari kehidupan yang tampaknya seketika atau permanen (Uman, 2008).

\subsubsection{Implementasi Konseling Eksistensial Dalam Mengatasi Trauma}

\section{Korban Bullying}

Dalam proses konseling eksistensial hubungan yang penuh kepedulian dan empati akan membantu proses terapeutik dalam konseling. Langkah-langkah proses konseling dilakukan dalam tiga tahap sesuai dengan prosedur konseling dan menggunakan salah satu teknik konseling eksistensial. Contoh kondisi klien sebelum treatment merasa gelisah karena takut mengalami tindakan bullying yang ia pernah alami ketika pergi ke sekolah sehingga tidak memiliki semangat untuk sekolah dan sulit berkonsentrasi di sekolah. Proses treatment dimulai dengan mengidentifikasi hal-hal yang klien rasakan dengan menciptakan suasana kepedulian empati sehingga muncul kepercayaan klien kepada konselor sehingga antara konselor dan klien bisa bekerja sama. Dalam proses mengidentifikasi konselor dapat melakukan keterampilan komunikasi melalui refleksi isi dan perasaan yang di sampaikan klien, dalam proses ini konselor juga mengajarkan bagaimana cara memahami sebuah eksistensi dan pemahaman tentang masalah yang dialami konseli dan sugesti-sugesti konseli terhadap dirinya kemudian setelah itu memberikan dorongan, semangat untuk perubahan pada dirinya dan 


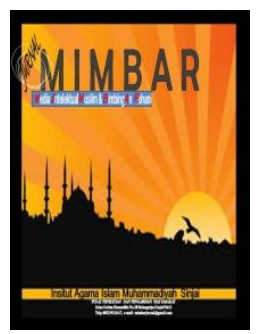

Volume 7, No. 2, 2021

ISSN (print) : 2442-3217 / ISSN (online) : 2716-3806

Email : mimbarjurnal@gmail.com

Homepage : http://journal.iaimsinjai.ac.id/indeks.php/mimbar

DOI : https://doi.org/10.47435/mimbar.v7i2

menciptakan pemahaman baru tentang dirinya dan merekonstruksi sikap-sikap dirinya terhadap sebuah masalah sehingga konseli mampu melaksanakan pilihannya dari pemahaman yang mereka pelajari dan mampu mempertanggung jawabkannya.

\section{PENUTUP}

Konseling eksistensial merupakan pendekatan yang menekankan pada kesadaran bahwa setiap individu memiliki potensi-potensi dan kebermaknaan diri. Dalam proses konseling hubungan konselor dan klien yang penuh kepedulian dan empati akan membantu proses terapeutik. Proses konseling dilakukan dalam tiga tahap dan fokus pada penangan masalah trauma korban bullying.

\section{DAFTAR PUSTAKA}

Coloroso, B. (2007). Extraordinary Evil: A Brief History of Genocide... and Why It Matters. Toronto, ON: Viking.

Corey, G. (2005). Teori dan praktek dari konseling dan psikoterapi. Terjemahan Oleh E. Koeswara. Jakarta: ERESCO.

Erford, B. T. (2016). 40 Teknik yang harus diketahui setiap konselor. In Yogyakarta: Pustaka Pelajar (Edisi Kedu). Pustaka Pelajar.

Olweus, D. (2006). Bullying in Schools: Facts and Intervention. In Update in Anaesthesia (Vol. 24, Issue 2). Research Center for Health Promotion, University of Bergen.

Sullivan, K., Cleary, M., \& Sullivan, G. (2003). Bullying in secondary schools: What it looks like and how to manage it. Sage.

Uman, S. (2008). Konsep \& Aplikasi Bimbingan dan Konseling. Madani Production. 